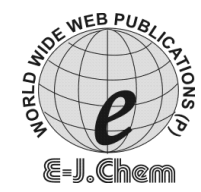

http://www.e-journals.net

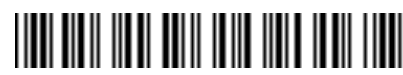

ISSN: 0973-4945; CODEN ECJHAO

E-Journal of Chemistry

Vol. 4, No. 3, pp. 313-319, July 2007

\title{
Potentiometric Studies on the Protonation Constants and Protonation Energies of Some Diamines in Methanol + Water Mixtures
}

\author{
SANGITA SHARMA*, MAYUR C. SHAH, NEHA PATEL, \\ DIPIKA DALWADI and J. J. VORA \\ Department of Chemistry, \\ Hemchandracharya North Gujarat University, \\ Patan-384 265. GUJARAT. \\ smridhee2000@yahoo.co.in
}

Received 9 November 2006; Accepted 12 December 2006

\begin{abstract}
The protonation constants of diamines such as ethylenediamine, 1,2diaminopropane, 1,3-diaminopropane, o-phenylenediamine, $m$-phenylenediamine, $p$-phenylenediamine were determined on the basis of Bjerrum and Calvin method in methanol-water mixtures. A pH metric method was used for calculation of protonation constants. The effects of solvents on protonation constant have been determined at ionic strength $0.2 \mathrm{M} \mathrm{dm}^{-3}\left(\mathrm{NaClO}_{4}\right)$ and temperature $30 \pm 0.1{ }^{\circ} \mathrm{C}$ under nitrogen atmosphere. FORTRAN (IV) programs were used for calculation of protonation constants and distribution of species like $\mathrm{H}_{2} \mathrm{~L}, \mathrm{HL}, \mathrm{L}$ in equilibrium state. The logarithm of the protonation constants decrease in aliphatic diamines and increase in aromatic diamines with increase in methanol content in mixed equilibria. The verification of constants are explained on the basis of solute-solvent interaction, solvation, proton transfer processes and dielectric constant of equilibria. Protonation energies have been calculated theoretically using computational methods and these protonation energies for aromatic diamines are higher than aliphatic diamines.
\end{abstract}

Keywords: Protonation constants, Diamines, Solvation energy and Solvent.

\section{Introduction}

A number of studies have been reported on protonation constants of $\alpha$-amino acids in different media $^{1-3}$. Acidity and basicity of a molecule is governed by its structure and solvent effects ${ }^{4-6}$. 
A review of literature has reveal that a little is reported for protonation constants of diamines in organic mixed solvents and organic-water solvents. Practically no literature is available on theoretical calculations of protonation energies of diamines. The present note explained the $\mathrm{pH}$ determination of stoichiometric protonation constants of diamines like Ethylenediamine, 1,2-diaminopropane, 1,3-diaminopropane, o-phenylenediamine, $m$-phenylenediamine, $p$-phenylenediamine in different methanol-water compositions. Protonation energies are also calculated using non semipirical methods of calculations. An attempt has been made to relate protonation energies of diamines to protonation constants.

\section{Experimental}

All diamines (ethylenediamine, 1,2-diaminopropane, 1,3-diaminopropane, o-phenylenediamine, $m$-phenylenediamine, $p$-phenylenediamine) used were of AR grade. Sodium perchlorate (Fluka), perchloric acid (Baker Analysed), Sodium hydroxide (Himedia) and methanol (E. Merck) were also used. Doubly distilled conductivity water was used for preparing methanol-water mixtures and stock solutions of diamines. Perchloric acid (0.2M) solution was prepared in water and potentiometrically standardized by earlier reported methods $^{7}$. Sodium hydroxide solution $(0.2 \mathrm{M})$ containing sodium perchlorate to maintain $0.2 \mathrm{M}$ ionic strength was prepared as $20,30,40,50,60,70$ and 80 percentage $(\mathrm{v} / \mathrm{v})$ in methanol-water solution and standardized using least square fit of Gran's plot for end point determination obtained from titration of perchloric acid with bases ${ }^{8-9}$. The required correction was made while carrying out the calculations. To determine the protonation constants of different diamines, a known concentration of $\mathrm{HClO}_{4}$ was added to diamine solution, the acidified solution was further neutralized with standardized $0.2 \mathrm{~N} \mathrm{NaOH}$ methanol-water solution.

$\mathrm{pH}$-metric titrations were performed for diamines in methanol-water containing $\mathrm{NaClO}_{4}$ in a jacketed glass reaction vessels as reported ${ }^{10}$. The $\mathrm{pH}$ metric readings were taken using system $361 \mu \mathrm{pH}$ meter assembly having combined electrode and temperature probe with readability $\pm 0.01^{\circ} \mathrm{C}$. The potentiometric cell was calibrated before each experiment to obtain the $\overline{\mathrm{pH}}$ values for each solvent mixture studied ${ }^{11}$ and calibration was checked intermittently. The ion products $\left[\mathrm{K} w=\left(\mathrm{H}^{+}\right)\left(\mathrm{OH}^{-}\right)\right]$were calculated at constant ionic strength of $0.2 \mathrm{M}$ (with $\mathrm{NaClO}_{4}$ ) in all methanol-water solutions . Aliquates of $50 \mathrm{~mL}$ of solution taken from test solution and transferred to the potentiometric cell and titrated against standard $0.2 \mathrm{M} \mathrm{NaOH}$ solution prepared in corresponding media. It is noted that the $\mathrm{pH}$ measurements in acid solution are rapid whereas a long time is required for equilibration in alkali solution, particularly in mixed solvents in case of e.m.f. measurements. Edsall and Blanchard $^{12}$, also noted that the measurements made in alkaline solution gave unstable e.m.f. readings.

\section{Results and Discussion}

Alkalimetric titration data were pruned by computer programs PKAS ${ }^{13}$. The values of the protonation constants given by the program were used as initial value for final refinement by computer program BEST ${ }^{14}$. FORTRAN (IV) computer program SPEPLOT ${ }^{15,11}$ was used to develop species distribution curves. Table 1 represent protonaion constants for diamines and Figure 1 show species distribution of ethylenediamine in $20 \% \mathrm{v} / \mathrm{v}$ methanol-water equilibria.

The stoichiometric protonation constants $\log \beta_{1}$ and $\log \beta_{2}$ are related to protoantion of $-\mathrm{NH}_{2}$ group of diamines by following equilibria. 
Table 1. Stoichiometric Protonation Constants $(\log \beta)$ of Some Diamines at $30 \pm 0.1^{\circ} \mathrm{C}$ for different Methanol-Water Mixtures. $\left(\mu=0.2 \mathrm{M} \mathrm{NaClO}_{4}\right)$

\begin{tabular}{|c|c|c|c|c|c|c|c|c|c|}
\hline Solvents & & $\begin{array}{c}0 \% \mathrm{M}- \\
100 \% \mathrm{~W}\end{array}$ & $\begin{array}{l}20 \% \mathrm{M}- \\
80 \% \mathrm{~W}\end{array}$ & $\begin{array}{l}30 \% \mathrm{M}- \\
70 \% \mathrm{~W}\end{array}$ & $\begin{array}{l}40 \% \mathrm{M}- \\
60 \% \mathrm{~W}\end{array}$ & $\begin{array}{l}50 \% \mathrm{M}- \\
50 \% \mathrm{~W}\end{array}$ & $\begin{array}{l}60 \% \mathrm{M}- \\
40 \% \mathrm{~W}\end{array}$ & $\begin{array}{l}70 \% \mathrm{M}- \\
30 \% \mathrm{~W}\end{array}$ & $\begin{array}{l}80 \% \mathrm{M}- \\
20 \% \mathrm{~W}\end{array}$ \\
\hline \multirow{2}{*}{ Ethylenediamine } & $\log \beta_{1}$ & 9.85 & 9.62 & 9.40 & 9.20 & 9.00 & 9.01 & 9.07 & 9.10 \\
\hline & $\log \beta_{2}$ & 16.79 & 16.74 & 16.64 & 16.39 & 16.21 & 16.14 & 16.00 & 16.93 \\
\hline \multirow{2}{*}{ 1,2-diaminopropane } & $\log \beta_{1}$ & 10.04 & 10.92 & 10.77 & 10.32 & 10.12 & 9.70 & 8.92 & 8.22 \\
\hline & $\log \beta_{2}$ & 16.69 & 15.40 & 15.38 & 15.19 & 15.10 & 14.72 & 14.40 & 14.20 \\
\hline \multirow{2}{*}{ 1,3-diaminopropane } & $\log \beta_{1}$ & 10.90 & 10.48 & 10.38 & 10.27 & 9.00 & 9.09 & 8.87 & 8.71 \\
\hline & $\log \beta_{2}$ & 19.75 & 18.69 & 17.69 & 16.38 & 16.31 & 16.29 & 15.98 & 15.68 \\
\hline \multirow{2}{*}{$o$-phenylenediamine } & $\log \beta_{1}$ & 4.61 & 5.53 & 5.63 & 5.70 & 5.73 & 5.78 & 5.73 & 5.89 \\
\hline & $\log \beta_{2}$ & 6.42 & 7.62 & 7.92 & 8.05 & 8.49 & 8.52 & 8.69 & 8.90 \\
\hline \multirow{2}{*}{$m$-phenylenediamine } & $\log \beta_{1}$ & 5.01 & 4.92 & 4.73 & 4.66 & 4.50 & 5.29 & 5.78 & 4.90 \\
\hline & $\log \beta_{2}$ & 7.57 & 8.01 & 8.25 & 8.33 & 8.49 & 9.29 & 9.77 & 8.98 \\
\hline \multirow{2}{*}{$p$-phenylenediamine } & $\log \beta_{1}$ & 6.22 & 6.70 & 6.60 & 6.54 & 6.45 & 6.80 & 7.52 & 6.01 \\
\hline & $\log \beta_{2}$ & 9.21 & 8.70 & 8.91 & 9.14 & 9.41 & 9.99 & 10.88 & 9.50 \\
\hline
\end{tabular}




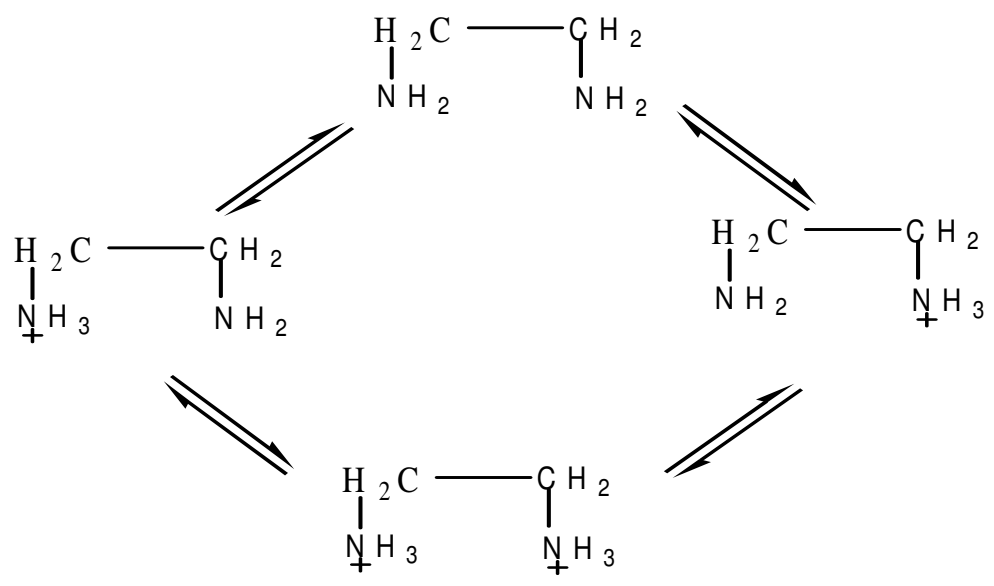

The $\log \beta$ values fall within the range of \pm 0.01 units not beyond \pm 0.02 in any case. In comparison of protonation constants obtained in methanol-water mixtures with published values in water shows that values in water are higher than those for aliphatic diamines but trend is different for aromatic diamines. The decrease in $\log \beta$ values of aliphatic diamines follow from the same course of decrease as observed in case of pyridine and Schiff derivatives with increase in organic solvent as in ethanol and are in good agreement ${ }^{16-17}$. Since methanol solvates B better than $\mathrm{BH}^{+}$, may be due preferential solvation of solute by one of the components of solvent mixture that could change the effective dielectric costant value in cibotactic region. This trend is also in agreement with data ${ }^{18-19}$ obtained for charged acids such as $\mathrm{BH}^{+}$. The data for aromatic diamines data show different results as compared to aliphatic diamines. The $\log \beta_{1}$ and $\log \beta_{2}$ value of aromatic diamines $(-o,-m,-p)$ showed increase with increase in percentage of methanol in solvent mixture. Aromatic diamines are less soluble in aqueous media as compared to aliphatic diamines $\& \log \beta_{1} \& \log \beta_{2}$ values in water are indicating that aromatic diamines are less basic than aliphatic diamine. Due to increase in solubility $\&$ association due to lower dielectric constants in water-methanol mixture leads to increase $\log \beta_{1} \& \log \beta_{2}$ values as compared to values in water.

The protonation constants have been considered in some detail to gain more information about the effect of solvent composition on protonation equilibria of diamines. For this purpose $\log \beta$ values are ploted against mole fraction $\left(\chi_{\text {methanol }}\right)$ of methanol-water mixtures. It was observed that $\log \beta$ values decreased or increased linearly with increase in concentration of methanol but the values determined in and above $70 \%$ methanol $\left(\chi_{\text {methanol }}\right)$ did not follow the linear trend observed in methanolwater mixtures. The linear equations (from $20 \%$ to $70 \%$ ) and related correlation coefficients for all the diamines were studied and were found to be in the range of 0.92 to 0.99 . The deviations of linearity for or above $70 \%$ methanol may result due to preferential solvation of solute by one of the components of solvent mixtures and could change in the effective dielectric constant value in the cybotactic region ${ }^{20}$.

Bates and coworkers ${ }^{18,21,22}$ examined the effect of change in solvent composition on dissociation of $\mathrm{BH}^{+}$and related Gibb's free energies of transfer in mixed solvents and found 
that electrostatic charging effects resulting from the change of dielectric constants with solvent composition are of minor importance in explaining the solvent effect. The $\log \beta$ values are related to reciprocal to dielectric constant of medium. So it is expected that as \% of methanol increases in mixtures, dielectric constant of medium decreases as compared to aqueous solution, also cybotactic region also decreases as dielectric constant of medium increases ${ }^{20,21}$. Further more, another factor which explain the increase or decrease of $\log \beta$ value of all diamines produced in methanol rich regions is the differences in solvent stabilization of ionic species like $\mathrm{HL}, \mathrm{H}_{2} \mathrm{~L}$ brought by changing the percentage of methanol ${ }^{18,22-25}$.

The unprotonated and protonated diamine species of stoichiometry L, HL, $\mathrm{H}_{2} \mathrm{~L}$ have been assumed in different chemical models. Species distribution diagrams shows that for aliphatic diamines $\mathrm{H}_{2} \mathrm{~L}$ species are maximum and are present in range of 99.6-99.9\% at lower $\mathrm{pH} 2.0$ and HL species are present at higher $\mathrm{pH} 7.1-9.3$. But in case of aromatic diamines $\mathrm{H}_{2} \mathrm{~L}$ species are found in the range of 50-99.5\% at lower $\mathrm{pH}$ 2.0 and HL species are present in range of 99.1 to $99.9 \%$ in $\mathrm{pH}$ range of 3.8-5.4. Both $\mathrm{H}_{2} \mathrm{~L}$ and $\mathrm{HL}$ species are present in acidic range of $\mathrm{pH}$ scale, which supports for higher acidic character of aromatic diamines in protonated form and difference in behavior from aliphatic diamines.

The protonation energies of selected diamines are calculated using Hyperchem software ${ }^{26}$. To calculate protonation energy two structures (i) unprotonated (ii) Two protonated were used as models for carrying molecular simulations. Charges were added at respective atoms. Ab-initio calculations (non-semi empirical methods) using minimal basis (STO-431G) are carried out. Geometry optimization conditions are specified as total charge $=1$ or 2 , spin multiplicity $=1$ or 2 , spin pairing $=$ RHF, Convergence limit $=0.01$, iteration limit $=50$ and acceleration convergence $=$ Yes . Total energies of protonated structure at SCF (Self Consistent Field level) with STO-431G basis are reported in Table 2. From these energy correlation protonation energies are computed. Geometry optimization minimum energy of protonated structures are higher than unprotonated structures for all diamines. Minimum energies calculated at SCF level for aromatic diamines are higher than aliphatic diamines. But protonation energies for aromatic diamines are lower than aliphatic diamines. The order of protonation energies for aromatic diamines is $o$-phenylenediamine $>m$-phenylenediamine $>p$-phenylenediamine. This order is reverse with respect to protonation constant values of these diamines. The order of protonation energies for aliphatic diamines is 1,2-Diamino-propane> Ethylenediamine $>1,3$-diaminopropane. In both aliphatic and aromatic diamines the porotonation energies is minimum for most basic diamine. Protonation energy of 1,2-diaminopropane is higher than ethylenediamine although protonation constant value of ethylenediamine is lower than 1,2-diaminopropane. Steric effect due to presence of $-\mathrm{CH}_{3}$ group near to one of the protonated sites $\left(-\mathrm{NH}_{2}\right)$ may be the probable cause for raising its energy. It can be generalized that more basic the diamine (aliphatic or aromatic) less is its protonation energy. More data is required to reach a definite conclusion. 
Table 2. Calculation of Protonation Energy and other Parameters in Various Diamine

\begin{tabular}{|c|c|c|c|c|c|c|c|}
\hline \multirow{3}{*}{ Name of diamines } & \multicolumn{6}{|c|}{ Energy, K Cal mole ${ }^{-1}$} & \multirow{3}{*}{$\begin{array}{l}\text { Protonation } \\
\text { Energy, } \\
\text { K Cal mole }\end{array}$} \\
\hline & \multicolumn{3}{|c|}{ Protonated } & \multicolumn{3}{|c|}{ Unprotonated } & \\
\hline & $\mathrm{SCF}$ & Gradience & Convergence & SCF & Gradience & Convergence & \\
\hline Ethylenediamine & -117744.03 & 5.024 & Yes & -117296.34 & 1.124 & Yes & 447.69 \\
\hline 1,2diaminepropane & -142195.82 & 135.26 & Yes & -141713.37 & 6.620 & Yes & 482.453 \\
\hline 1,3diaminepropane & -141903.23 & 40.149 & Yes & -141502.16 & 5.415 & Yes & 401.07 \\
\hline$o$-phenylenediamine & -211610.28 & 6.471 & Yes & -211164.32 & 21.323 & Yes & 445.96 \\
\hline$m$-phenylenediamine & -213897.04 & 10.294 & Yes & -213529.34 & 5.642 & Yes & 367.7 \\
\hline$p$-phenylenediamin & -214150.61 & 12.422 & Yes & -213867.27 & 7.417 & Yes & 283.339 \\
\hline
\end{tabular}




\section{References}

1. Herbert S H and Birsdsall C M, J. Am. Chem. Soc., 1961, 417.

2. Nowak B and Pawlak Z, J. Am. Chem. Soc., 1943, 65, 54.

3. Sharma Avinash, Gupta K. D. and Sexsena K. K., J. Indian Council of chemists, 2002, 19(2), 43.

4. Taf R W, Prog. Phys. Org. Chem., 1983, 14, 247.

5. Hens J, Structural effects on equilibria in organic chemistry; Wiley: New York, 1975.

6. Boyles J W \& Taylor A F, J. Am. Chem. Soc., 1943, 65, 54.

7. Jeffery G H, Bassett J, Mendham J and Denney R C, Vogel's Text book of Quantitative Chemical Analysis; $5^{\text {th }}$ Ed. ,Addition Wesley Longman Ltd: England, 1991, 326.

8. Gran G, Analyst, 1952, 77, 661.

9. Gran G, Anal Chem. Acta., $1988,206,111$.

10. Martell A E and Motekaitis R J, Determination and Use of stability constants; VCH Publishers: New York, 1992, 4.

11. Motekaitis R J and Martell A E, Can. J. Chem., 1982, 60, 168, 2403-2409.

12. Edsall J J and Blanchard M H, J. Am. Chem. Soc., 1933, 55, 2377.

13. Motekaitis, R J and Martell A E, Can. J. Chem., 1982, 60, 168.

14. Motekaitis R J and Martell A E, Can. J. Chem., 1982, 60, 2403.

15. Sillen L G and Martell A E, Stability constants, Special publication No. 7, The Chemical Society, London, 1964.

16. Niazi MSK and Mollin M, J. Bull Chem. Soc., Japan, 1987, 60, 2605.

17. Panichajakul C C and Wooley E M, Analyst Chem., 1975, 47, 1880.

18. Bates R G, Electro J. Anal. Chem., 1971, 29, 1.

19. Ligny De CL, Recueil, 1960, 79, 731.

20. Issacs N S, Physical Organic Chemistry, Longman, New York ,1986.

21. Samuel Glasstone, An Introduction to Electrochemistry, Affiliated East-West Press Pvt. Ltd, New Delhi, 1942.

22. Paabu M, Bates R G and Robinson R A, J. Phy. Chem., 1965, 70, 247.

23. Bates R G, Determination of pH theory and practical, Wiley, New York, 1973.

24. Gunuduz T, Kilhe E, Canel E \& Kosseoglu F, Anal. Chim. Acta, 1993, 282, 489.

25. Kihe E, Kosseoglu F\& Bargalo, Anal. Chim. Acta, 1994, 294, 215.

26. Computation Chemistry Manual for Hyperchem ,Version 4 ,Hypercube Inc. 419 Pheli P Street, Waterloo, Ontario, Canada 21, $8 \mathrm{X}_{2}$. 


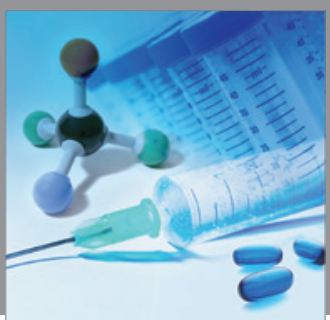

International Journal of

Medicinal Chemistry

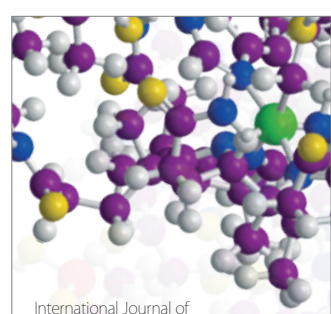

Carbohydrate Chemistry

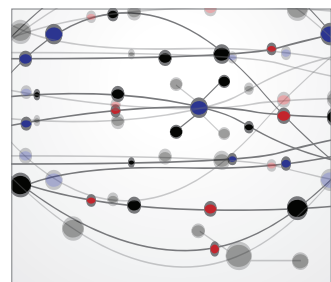

The Scientific World Journal
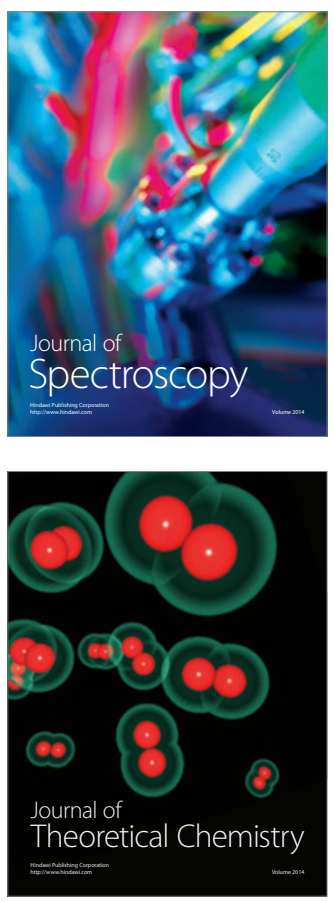
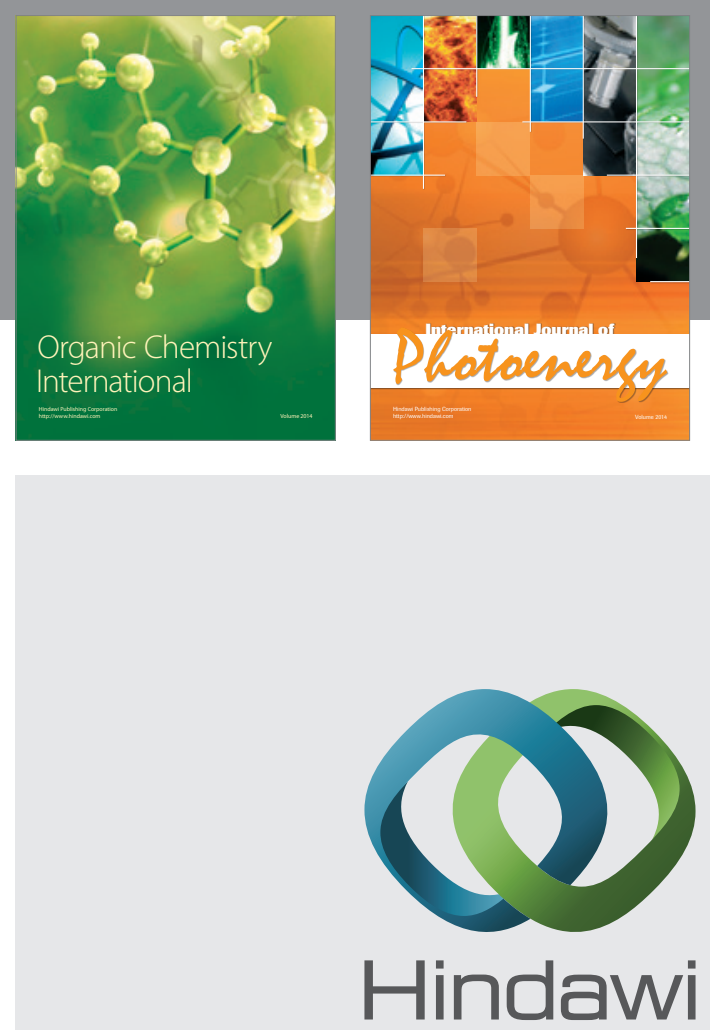

Submit your manuscripts at

http://www.hindawi.com
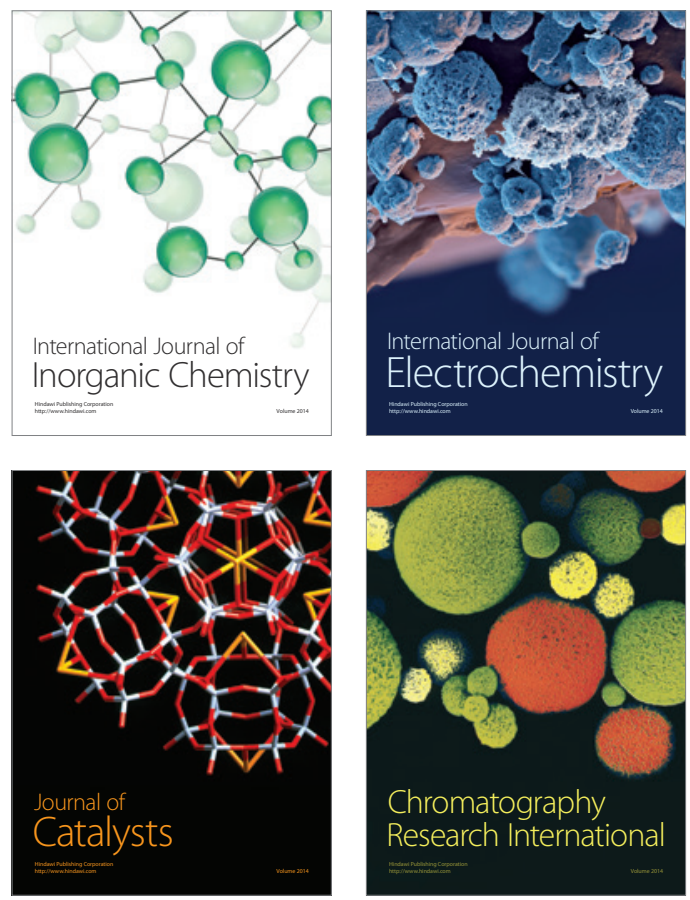
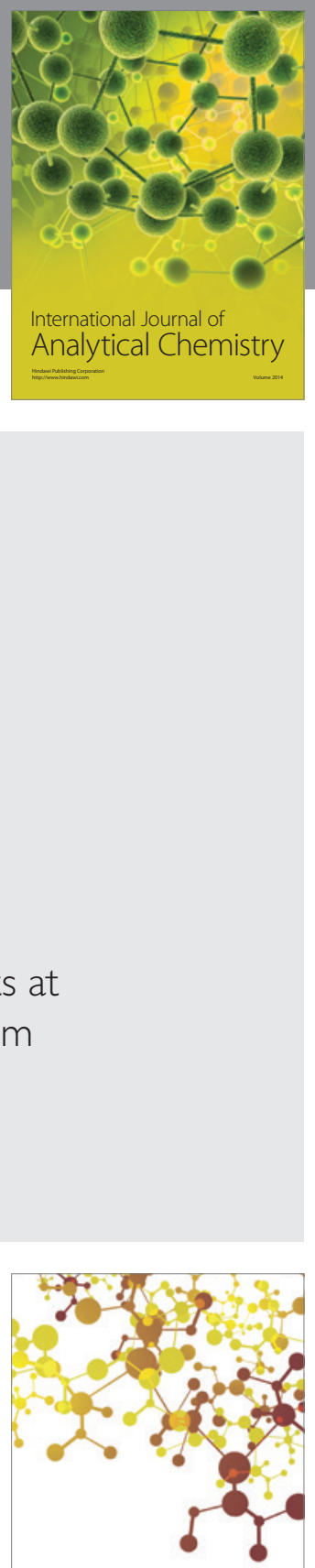

Journal of

Applied Chemistry
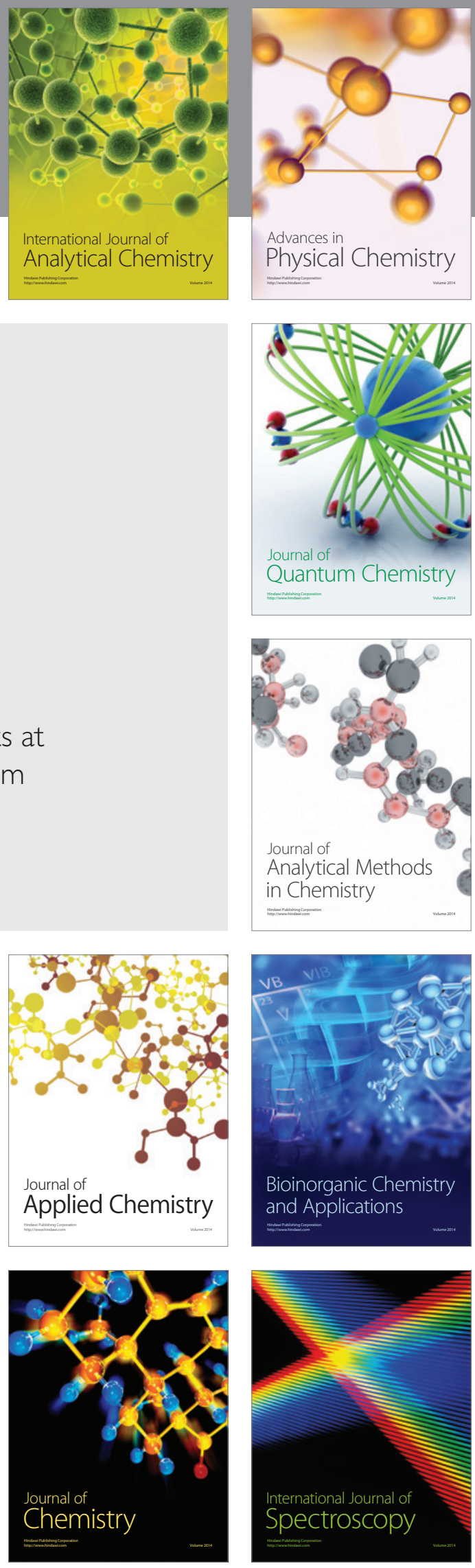